\title{
A Systems Approach to Combat Workplace Sexual Harassment
}

\author{
Mrs Rajani Suresh, Dr. Sambatur Sridhar and Ms Sneha S Kairanna \\ ${ }^{1}$ Affiliation: Assistant Professor, St Aloysius Institute of Management and Information Technology (AIMIT) \\ ${ }^{2}$ Postal Address: Sharada Nagar, $2^{\text {nd }}$ Cross, Kotekar Post Madoor, Mangalore 575022
}

\begin{abstract}
Sexual Harassment affects all women in some form or the other. Sexual Harassment at work is an extension of violence in everyday life and is discriminatory, exploitative, thriving in atmosphere of threat, terror and reprisal. Sexual harassment of women in organizational settings has recently become a topic of interest to researchers and the general public alike. Although numerous studies document its frequency, the development of conceptual models identifying antecedents and consequences of harassment has proceeded at a slower pace and is almost nonexistent in the Indian context. This paper presents a conceptual model of sexual harassment in the workplace using the systems thinking approach.
\end{abstract}

Key words: Sexual harassment, legal framework, employer obligation, systems thinking, conceptual model

\section{Introduction}

Sexual harassment is a form of destructive workplace communication that has damaging, sometimes devastating, effects on the individuals involved, those connected to them, and organizations as a whole. The problem of sexual harassment occurs ubiquitously across job sectors and has defied attempts at prevention through policy and training initiatives. During the last decade some progress has been made in the development of theories of sexual harassment and with the passage of time these theories have become increasingly diverse, complex, and sophisticated. As the social sciences become increasingly sophisticated about the inadequacy of single and sovereign theories about any realm of social behaviour, it is perhaps inevitable that a comprehensive theory of sexual harassment will require incorporating factors operating at several levels of social life (Kamal, 1998). In some cases the same explanatory construct appears at several levels of analysis, the prime example being "power"" which operates at cultural, organizational, and individual levels. As a result, no single explanation covers the full range of phenomena labeled sexual harassment. (Brewer \& Berk, 1982; Cleveland \& Kerst,1993; Tangri, Burt, \& Johnson, 1982). None of the literature has demonstrated that any one "cause" is both necessary and sufficient condition for sexual harassment. (Kamal, 1998).

\section{Combating sexual harassment in the Indian workplace: Is Legislation alone enough?}

In stark contrast to the global research effort, research on sexual harassment in Indian workplace is still in its beginning stages. In India, many allegations of sexual harassment have cropped up in the very year in which a law to prevent such harassment at the workplace was enacted. This clearly reveals that laws are not enough to stop such abuse, as well as other forms of violence against women. At the same time, the sense of empowerment such laws have afforded women has encouraged many to come out in the open to protest such attacks on their personal integrity. The Sexual Harassment of Women at the Workplace (Prevention, Prohibition and Redressal) Act, 2013, was a codification of the "Vishaka Judgment" ${ }^{1}$ on guidelines for employers to institutionalize mechanisms to provide redressal to victims of such abuse at the workplace.

The case of the beleaguered editor of Tehelka, Tarun Tejpal, the allegations by law interns against two retired Supreme Court judges in the recent past, and scores of others that followed in private and public workplaces have, for the first time, brought the topic of workplace sexual harassment on to the wider debating platforms of the country.

Most sexual crimes against women in India, however still go unreported. This is primarily because extant assumptions of patriarchy, power and control over women allow such crimes to happen and make it all that more difficult for women to report them. Sexual harassment of women at the workplace is aided by skewed gender equations in the organizational hierarchy.

The law in India now makes a clear link between sexual harassment and the violation of fundamental rights to equality of a woman. It is also clear that for the law to be effective, each organization and institution must put in place, on pain of strict penalty, the required bodies and mechanisms to deal with such violations.

But will law alone eradicate this scourge? No. Harassment at the workplace is often about abuse of power by a "superior", and change in mindset of the oppressor and the victim and a strict application of the law and commensurate punishment for offenders might help victims to report it. 
There is therefore a pressing need to devise a more comprehensive mechanism that compliments and acts in conjunction with the existing legal regime to tackle sexual harassment at the workplace. This paper proposes that the systems thinking approach will provide a way out of this wicked problem.

\section{Vishaka v. State of Rajasthan, (1997) 6 S.C.C. 241 (India) \\ Systems thinking as an Effective Approach to Manage wicked problems}

Systems' thinking is an approach for developing models to promote our understanding of events, patterns of behavior resulting in the events, and even more importantly, the underlying structure responsible for the patterns of behavior. If we are interested in addressing a complex problem like sexual harassment, it is only through our understanding of the underlying structure that we will be able to identify the most appropriate leverage points to effect change within the system.

Systems' thinking is a way of seeing the connections, links, or relationships between the antecedents, determinants, concomitants and consequences and the reinforcing and balancing feedback process of sexual harassment. Instead of seeing parts and pieces of how harassment happens, it allows the interdependent whole to be appreciated. It is a process for understanding the interrelationships among key components of the sexual harassment system, such as: hierarchical relations, process flow, attitudes and perceptions. Systems' thinking helps to uncover the living connections between things large and small. After a while, what emerges is recognition of underlying structures to a complex situation like sexual harassment - and that often shows up in the form of archetypes. Mapping and analyzing sexual harassment at the systems level allow a careful tracking of factors affecting input, processes, output and outcomes that might otherwise have remained invisible or misunderstood. Sexual harassment is a complex social problem involving multiple actors and dealing with this problem is notoriously difficult. Conventional solutions to the problem of sexual harassment, like legal protection to victims and stringent punishment to perpetrators while good on paper, are of limited practical efficacy, unless coupled with affirmative action.

\section{The Systems Thinking Approach}

The approach of systems thinking is fundamentally different from that of traditional forms of analysis. Traditional analysis focuses on separating the individual pieces of sexual harassment; in fact the word "analysis" actually comes from the root meaning, "to break into constituent parts". Systems' thinking in contrast, focuses on how the antecedents and concomitants of harassment interacts with the process of harassment- to produce unacceptable behavior -which is a part of workplace sexual harassment. This means that instead of isolating smaller and smaller parts of the system being studied, systems' thinking works by expanding its view to take into account larger and larger number of interactions as an issue being studied. This results in sometimes strikingly different conclusions than those generated by traditional forms of analysis, especially when what is being studied is a wicked social problem like workplace sexual harassment

\section{Defining Sexual Harassment}

There are two main approaches to defining sexual harassment: One from a legal perspective and the other from a social-psychological perspective. In India -The Sexual Harassment of Women at Workplace (Prevention, Prohibition and Redressal) Act, 2013, was passed "to provide protection against sexual harassment of women at workplace and for the prevention and redressal of complaints of sexual harassment". While no comprehensive legal definition is provided in the Act, in general, social-psychological definitions are broader than legal ones, though recent exceptions exist

Perhaps, the most frequently asked question about sexual harassment tries to determine which specific behaviors constitute sexual harassment. Such research approaches the study of sexual harassment by analyzing which aspects of these patterns of behaviour are unwanted. In defining sexual harassment, the sexual advance, request for sexual favours, sexually verbal or physical conduct must be "unwelcome". In other words, the complaining individual must show that he or she did not want, invite, solicit or encourage the sexual conduct in order to prove that sexual harassment actually occurred. A truly consensual sexual relationship or sexual conduct, in which the alleged victim willingly participated or set in motion, may not be considered unwelcome and hence, is not sexual harassment (Roumell \& Danlene, 1999). Additionally, further contention occurs in the fact that when the courts consider whether sexual conduct was unwelcome, they look at all circumstances and concentrate on the alleged victim, not the alleged offender's intent. Reid (2004) broadly describes sexual harassment as a form of unlawful sex discrimination. A spectrum of behavioural patterns may signify sexual harassment (Figure 1). 
TABLE 2.1 SEXUAL HARASSMENT: A SPECTRUM OF BEHAVIOURAL PATTERNS

\begin{tabular}{|c|c|c|c|c|c|c|}
\hline Visual & Verbal & Written & Touching & Power & Threats & Force \\
\hline $\begin{array}{l}>\text { Ogling } \\
>\text { Staring } \\
>\text { Posters } \\
>\text { Magazines } \\
\text { Flyers }\end{array}$ & $\begin{array}{l}>\text { Requests for } \\
\text { dates } \\
>\text { Questions } \\
\text { about } \\
\text { personal life } \\
>\text { Lewd } \\
\text { comments } \\
>\text { Dirty/Sexual } \\
\text { jokes } \\
>\text { Whistling }\end{array}$ & $\begin{array}{l}\text { Love poems } \\
\text { > Love letters } \\
>\text { Obscene } \\
\text { poems } \\
\text { Obscene } \\
\text { letters } \\
>\text { Cards }\end{array}$ & $\begin{array}{l}\text { Violating } \\
\text { space } \\
\text { Patting } \\
\text { Grabbing } \\
\text { Pinching } \\
\text { > Caressing } \\
\text { Kissing }\end{array}$ & $\begin{array}{l}\text { Relationships } \\
\text { Using position } \\
\text { to request } \\
\text { dates, sex, etc. }\end{array}$ & $\begin{array}{l}\text { "Quid pro quo" } \\
\text { Demands } \\
>\text { Loss of job } \\
\text { Selection } \\
\text { process }\end{array}$ & $\begin{array}{l}\text { Rape } \\
\text { Physical } \\
\text { assault }\end{array}$ \\
\hline 4 & $\begin{array}{l}\text { Offensive } \mathrm{C} \\
\text { (May be ille }\end{array}$ & $\begin{array}{l}\text { Conduct } \\
\text { legal) }\end{array}$ & & & $\begin{array}{l}\text { Demands } \\
\text { Illegal in all cases) }\end{array}$ & 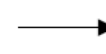 \\
\hline \multicolumn{4}{|c|}{$\begin{array}{l}\text { Individual perceptions and reactions determine harassment } \\
\text { Behaviours unwanted by recipients are harassment } \\
\text { Behaviours may not be intended to harass, but that is often } \\
\text { the result } \\
\text { Illegal if the result is perceived as harassment }\end{array}$} & \multicolumn{3}{|c|}{$\begin{array}{l}\text { Behaviours are intentional; goal is to intimidate, } \\
\text { harass, or hurt another person }\end{array}$} \\
\hline
\end{tabular}

Source: Grobler, Wärnich, Carrell, Elbert and Hatfield, (2002:60)

An integrated approach to sexual harassment through Systems Thinking

Systems' thinking helps to uncover the living connections between things large and small. After a while, what emerges is recognition of underlying structures to a complex situation - and that often shows up in the form of archetypes. Mapping and analyzing at the systems level allow a careful tracking of factors affecting input, processes, output and outcomes that might otherwise have remained invisible or misunderstood.

There is no perfect law, perfect policy or perfect procedure which can combat sexual harassment on its own. This is because of the numerous linkages and connections between the antecedents, concomitants and consequences of workplace sexual harassment. A Systems Thinking approach can be used to create a model that clearly reveals these linkages and connections.

Sexual harassment is a wicked problem. Therefore, it is nearly impossible to design a complaint system that users will think is satisfactory. Once harassment has occurred, it is difficult to bring about any resolution that is wholly positive. This virtually guarantees that harassment policies and complaint systems have an unsatisfactory reputation. In an ideal system, a high proportion of complainants would feel satisfied, most respondents would feel fairly treated, and most complaint handlers would feel they acted fairly. In actuality, the complainant's pain is often long lasting. Any steps that can be taken after harassment has occurred may lead to feelings of more injury.

\section{Sexual Harassment-Conceptual Model Using The Systems Thinking Approach}

There could not be anything less fundamental to systems theory than the ubiquitous input-output model. This paper creates a conceptual model of sexual harassment in the Indian workplace using the systems approach.

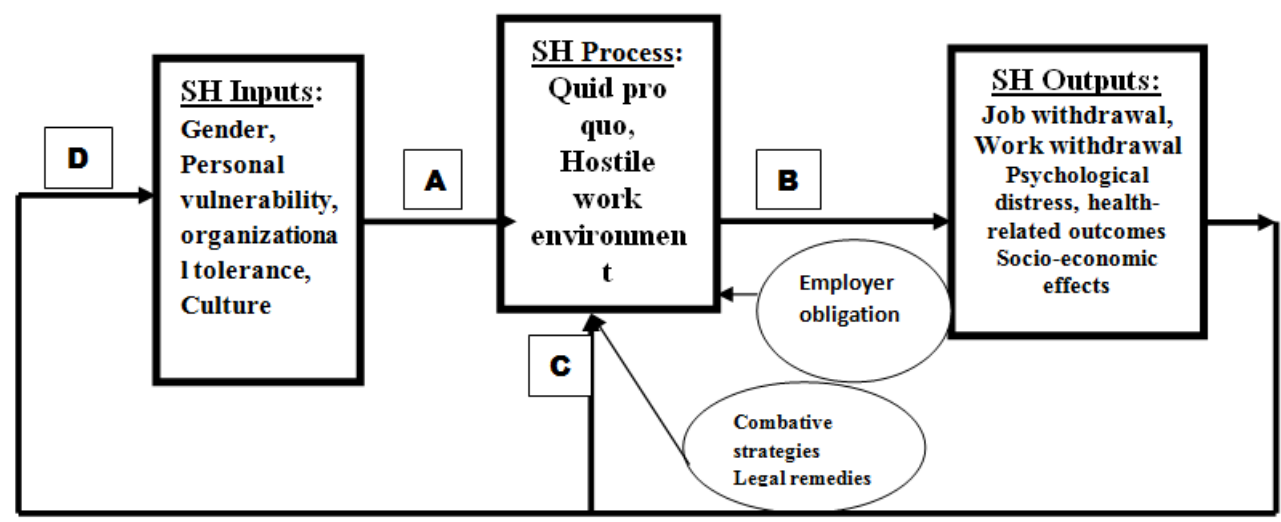

\section{Personal vulnerability}

\section{Antecedents Of Sexual Harassment}

While women as a group are victimized by sexual harassment, not all women are equally vulnerable. Particularly, women who lack cultural power and status advantages are especially apt to be the targets of sexual harassment. Young, unmarried, and minority women have been found to be the target of severe, persistent harassment (Gruber and Bijen, 1982; Lafontaine \& Tredeau, 1986). Fitzgerald, Hulin, and Drasgow, (1994) 
have grouped these characteristics into personal vulnerability, which they consider to be a moderating variable in their integrated model.

\section{Organizational context}

The organizational context in which a woman must perform has been implicated as a possible antecedent to harassing behaviour. Gutek \& Morasch's (1982) sex-role spillover model proposes that in occupations dominated by one sex or the other, the gender role of the predominant group influences the work role expectation for that job, and the treatment of women within the work group. Indeed, survey data suggest that unbalanced sex ratio with respect to the job and the work setting are related to experience of sexual harassment among working women (Terpstra \& Baker, 1986). Research has found that women in nontraditional jobs (who naturally possess less formal power) were more extensively harassed than women in other occupations (Lafontaine \& Tredeau, 1986). According to the integrated model (Fitzgerald, Hulin, \& Drasgow, 1994), sexual harassment is a function of organizational context and job context.

\section{Gender}

Sexual harassment is a clear form of gender discrimination which relates not so much to the actual biological differences between men and women, but to the gender or social roles which are attributed to men and women in social and economic life, as well as perceptions and expectations about male and female sexuality in society. Women are expected to be compliant and sexually passive and men are socialized to believe that they are the ones to initiate sexual relationships and that it is reasonable, tolerated or even expected of them to be sexually aggressive. While men may be subjected to sexual harassment, existing literature and the findings of the country studies affirm that the majority of victims are women.

\section{Process of sexual harassment}

Sexual harassment may take two forms:

1) Quid Pro Quo, when a job benefit - such as a pay rise, a promotion, or even continued employment - is made conditional on the victim acceding to demands to engage in some form of sexual behavior; or;

2) Hostile working environment in which the conduct creates conditions that are intimidating or humiliating for the victim. Regardless of whether it actually results in psychological harm to the victim, which may well be the case, it is now known to constitute an environment of hostility or abuse towards one or more employees. The responsibility to correct and remedy this environment is placed on the employer. (Teresa Harris, 1993)

Sexual harassment is composed of three separate dimensions: gender harassment, unwanted sexual attention, and sexual coercion (Fitzgerald, Gelfand, \& Drasgow,1995; Gelfand, Fitzgerald, \& Drasgow, 1995. Gender harassment is characterized by insulting, misogynistic, and degrading remarks and behavior, that are not designed to elicit sexual cooperation but that convey hostility and degrading attitudes toward women. Unwanted sexual attention consists of unwelcome sexual behavior that is undesired and unreciprocated by the recipient, but not tied to any job-related reward or punishment. Sexual coercion refers to implicit or explicit threats or promises of job-related outcomes, pertaining to sexual favors. The first two factors are conceptually similar to the legal concept of hostile work environment, where as the last more closely corresponds to the concept of quid pro quo harassment.

\section{Combative Remedies that can influence the process of sexual harassment}

The issue of workplace sexual harassment is a grey area even in western economies that have a potentially large and assimilated female workforce compared with India. However, unlike western countries where organizations accept workplace harassment in normal parlance, in India it was always frowned upon as a non-issue. Therefore a robust legal mechanism will go a long way in creating a congenial work environment and providing for the constitutional mandate of safety and security for Indian women.

\section{Legal mechanisms and legal protection in India}

In India, the Constitution provides equal rights and opportunities for women; but in practice the women employees face various problems like lack of safety, sexual harassment from superiors and colleagues etc. Theoretically, the range of legal redress available for sexual harassment covers constitutional, criminal, tort, and civil law. In practice, however, prior to the Vishaka decision, there was no law preventing sexual harassment at the workplace in India. Sexual harassment was not regulated by any of the labour or employment legislations. To some extent, traditional criminal law provisions under the Indian Penal Code (IPC) criminalized some forms of sexual harassment with the aim to preserve women's modesty. They were not effectively enforced, and at any rate, were not understood as aimed at promoting gender equality. 
Laws under the Indian Penal Code include:

Section 209: Obscene acts and songs, to the annoyance of others;

Section 354: Assault or use of criminal force on a woman with intent to outrage her modesty;

Section 376: Rape;

Section 509: Uttering any word or making any gesture intended to insult the modesty of a woman.

Recent amendments

The Sexual Harassment of Women at Workplace (Prevention, Prohibition and Redressal) Act, 2013

Criminal Law (Amendment) Act, 2013, Section 354 (A) was added to the Indian Penal Code that stipulates what consists of a sexual harassment offence and what the penalties shall be for a man committing such an offence.

Penalties range from one to three years imprisonment and/or a fine. Additionally, with sexual harassment being a crime, employers are obligated to report offences. However, criminal law covers only severe forms of sexual harassment involving rape or physical assault, and requires a high degree of proof. Tort law, on the other hand, offers an avenue for compensation based on proof of damage suffered but remains an undeveloped area of law in India.

\section{Judicial Activism}

Gender justice has been a burning issue in the last decade in India, especially in light of the increase and focus by non-Governmental organizations and related women's groups dealing with such issues enabling the emergence of an aware and educated civil society. With the emergence of a strong brand of judicial activism by the Supreme Court of India, the rights of women have been given immense importance by the courts, even where the legislature has failed to enact laws to this effect.

Despite these reforms, more than seventeen years since the Vishaka judgment, change in the workplace is still moving very slowly. The majority of employers still do not have Complaints Committees established. Apart from a few public sector bodies, universities, and some large private companies, Complaints Committees have not been set up on a large scale. Complaints Committees are often hurriedly established when employers receive a complaint of sexual harassment. Even when they are constituted, they remain largely non-functional. (Sheba Tejani, 2004)

In many recent cases, there have been a series of recent high-profile cases where allegations of sexual harassment have been made by senior women officers in the government, there was high media coverage, and ultimately the cases were hushed up and closed, and the women who complained of sexual harassment were dismissed from service. The victimization of women who complain of sexual harassment has become a regular practice. "It is a classic case, where the complainant has become the accused, and the accused became the complainants." (TOI, 2009)

\section{Legal prohibition versus an affirmative duty to act}

A relatively new development is not only to prohibit sexual harassment in legislation but to provide for an affirmative duty to prevent it. The Supreme Court decision in Vishaka insists on affirmative action by the employer. This measure provides employers with a significant incentive to take preventative measures against sexual harassment. The benefits of holding employers liable, in addition to the perpetrators, are foremost that employers may be the best placed to ensure that the harassment stops. They may also be the only ones able to remove the harasser from the complainant's working environment or to remedy the harm caused by the harassment such as loss of salary, promotion, training, or other opportunities.

\section{Combative strategies}

\section{Preventive mechanism- Employer obligation to respond proactively}

Effective legal remedies are necessary. However, the main aim of most victims of sexual harassment is not to sue their employer for damages, but that the offensive behavior should stop, that it should not recur and that they should be protected against retaliation for having bought a complaint. Therefore, the most effective way to deal with sexual harassment is to develop and implement a preventive policy at enterprise level. The employer should abide not only by the letter but also by the spirit of the law. He must ensure that robust mechanisms exist in the workplace that definitely ensuring the sanctity and neutrality of the complaint investigation process. Thus, the resolution largely depends on robust internal systems, privacy and the ability to safeguard the reputations of the aggrieved, the accused and the organization.. A fair and neutral investigation system, the right and opportunity to express, better and equitable work conditions and suggested exceptions, as the case might be, are other important components of a robust system.

Throughout Asia and around the world, governments, employers' and workers' organizations and NGOs are increasingly advocating that sexual harassment be addressed through workplace policies and complaints procedures. This trend reflects the recognition that workplace policies can be a most effective tool 
for preventing sexual harassment. It has become increasingly apparent over recent decades that legislative measures for combating sexual harassment need to be accompanied by preventive mechanisms introduced at the workplace level. The biggest ground yet to be covered is in educating and sensitizing employees. Some organizations have one-off workshops for department heads, but make no effort to ensure the message filters down. In order to facilitate the development of a healthy work environment organizations have to create effective policy framework and communicate it at regular intervals so that it comes alive through campaigns and creative platforms. They must demonstrate a culture of zero tolerance to workplace sexual harassment.

\section{Consequences of Sexual Harassment}

Considerable data have been accumulated, confirming that harassment is widespread in both the public and the private sectors, and that it has significant consequences for employee health and psychological well being (Fitzgerald, 1993; Schneider, Swan \& Fitzgerald, 1997). Crull (1982) found that the majority of harassed women reported negative outcomes related to work performance (75\%), psychological health $(90 \%)$, and physical health (63\%). A review by Gutek and Koss (1993) also suggested that the impact of sexual harassment has been examined within at least three domains: psychological, physical, and work-related. Within each area, victims of sexual harassment report numerous consequences. Psychological effects include lowered selfconfidence, decreased self-esteem, increased stress, depression, frustration, anxiety, irritability, and anger (Crull, 1982; Dan et al., 1995; Gruber \& Bijorn,1982; Gutek \& Koss, 1993, Loy \& Stewart, 1984). Physical effects include stomachaches, headaches, sleep disturbance, nausea, and bursting out in tears (Crull, 1982; Dan et al., 1995, Gutek, 1985). Work-related effects include difficulty with inter personal relations, decrements in job performance, job loss and career interruption (Crull, 1982; Gruber \& Bijen, 1982; Gutek, 1985; Linvigston, 1982; Loy \& Stewart, 1984).

Sexual harassment produces a host of negative consequences (ILO, 2001). The various types of impact on individual workers (i.e. victims), business enterprises, and societies as a whole include:

\section{On victims}

(a) Physiological effects

Victims of sexual harassment suffer in a variety of ways, but common physiological effects include nausea, loss of appetite, headaches, and fatigue, which can lead to increased absenteeism. The trauma associated with sexual harassment can also cause miscarriage in pregnant women. Moreover, in the absence of adequate support systems, including psychological counseling and medical care, the physiological effects of harassment can result in chronic illness, which then further impairs both the victim's ability to work and her overall quality of life. (CEDAW, 1992).

\section{(b) Psychological effects}

Common psychological effects of sexual harassment include humiliation, shame, anger, fear, anxiety, depression, and decreased motivation. Psychological outcomes refer to both stress-related reactions such as anxiety and depression; and health-related outcomes include reactions such as headaches, gastrointestinal disorders, and sleep disturbance. In extreme cases, the resulting trauma may lead victims to commit suicide. Without proper counseling, psychological suffering can lead to a total loss of interest in work, or to a debilitating fear of going outside or of being alone.

\section{(c) Socio-economic effects}

Victims of sexual harassment can also suffer economically as a result of the offending behaviour. A loss in concentration and hence productivity affects opportunities for advancement, which in turn lowers earning capacity, especially for those paid daily or on the basis of output produced. A victim who refuses the advances of a superior may be fired, or feel forced to resign if management is unsympathetic to her situation. Such loss of employment or a decrease in earning power may then force her into economic dependence on others, placing a victim in a precarious situation and exacerbating her risk of suffering other forms of gender-based violence "(ILO, Nepal,2004)

Perhaps worst of all is the social stigma attached to sexual harassment in conservative India. Once a woman is sexually harassed - but especially if she lodges a complaint - her character comes under question and this can jeopardize her other social relationships, for instance in her family, leading to "neglect, hatred, domestic violence, [or] divorce".(ILO, Nepal,2004)

\section{On enterprises}

Although sexual harassment inflicts the most devastating effects on its victims, business enterprises also incur certain costs associated with the tolerance of these phenomena, and an absence or lack of existing and effective preventive, investigative, and remedial measures. For instance, sexual harassment "undermines 
equality at the workplace by calling into question individual integrity and the well-being of workers; it damages an enterprise by weakening the bases upon which work relationships are built and impairing productivity." It also harms productivity by increasing "workplace tensions, which [...] may impede teamwork, collaboration and work performance", before finally resulting in increased absenteeism and decreased productivity (ILO, 1996). Sexual harassment negatively affects job, psychological, and health-related outcomes. Job outcomes include factors such as job satisfaction and organizational withdrawal. Job outcomes reflecting stress-related cognitions and voluntary behaviors (in addition to the more frequently cited consequences of involuntary job loss and career interruption; e.g., Coles, 1986) are related to sexual harassment.

\section{On societies}

Besides affecting victims and business enterprises, sexual harassment also produces negative outcomes for entire societies. Tolerance of such behavior "impedes the achievement of equality between men and women, it condones sexual violence[,] and...[i]t is wasteful from economic, social and human resource development points of view to invest only in selected parts of the population [as a result of] discrimination based on sex...”.(ILO 2001).

\section{Further scope: an Integrated Model of Sexual Harassment in Organizations}

An integrated model suggesting that sexual harassment is a function of organizational context and job context, with personal vulnerability and response style characteristics acting as moderators can be applied in the Indian context. Fitzgerald, Hulin, and Drasgow (1994) developed such an integrated model suggesting that sexual harassment is a function of organizational context and job context, with personal vulnerability and response style characteristics acting as moderators. In turn, sexual harassment is thought to contribute to three sets of outcomes (psychological, health, and job-related) that ultimately can result in work or job withdrawal.

Severity of sexual harassment is a strong predictor of the degree to which women suffer negative psychological, physical, and job related outcomes (Fitzgerald et al., 1995). This model could be tested in the Indian context.

As we understand so little about sexual harassment in India, this further testing should explore the nature of sexual harassment in the workplace, and drawing upon theoretical models as well as previous research to identify variables that are likely to be antecedents and consequences of sexual harassment. This study should include (1) personal vulnerability, (2) organizational context, (3) victim's response styles (assertive, non assertive), (4) outcome variables, (ie, work related, psychological, physical), and the relationship amongst them and types of sexual harassment (gender harassment, unwanted sexual attention, sexual coercion.

\section{Conclusion:}

Sexual harassment is an offence that contains numerous intersecting issues of human rights, gender equality, dignity, health, work conditions, productivity, freedom to practice and chose one's profession, right to livelihood, to name a few, since it impacts on all these areas. As explained, if workplaces are not made free of discrimination for women, then a community is set-back. More importantly, it personalizes silences and makes invisible, a systemic pattern of violations in the workplace and puts women at risk.

Civil law goes a step further in distributing legal obligations among stakeholders in the workplace to build consciousness against sexual harassment as well as to protect and provide redress to victims. In addition to this, criminal and tort actions, since all applicable courses of actions are simultaneously available and offer different opportunities for redress.

Legal recourse, however, comes with risks and limitations. Its outreach and enforcement in the context of poverty, illiteracy and unorganized labour in many parts of India is a challenge for legal systems that are distant and inaccessible to the poor generally, and women in particular. In the case of women's issues, the law more often than not, reproduces and reinforces dominant gender stereotypes of the 'good' and 'bad' woman, shifting scrutiny upon the victim, her behavior, morality, dress, and so on, rather than the harasser, the workplace code of conduct, and employer responsibility.( Krishnan, Suneeta,2013)

These contested issues and barriers highlight the limited nature of relief that law provides. The crafting of a comprehensive law in and of itself would offer a normative respite but one must remain mindful of public education and training inputs that would help challenge the gendered interpretation and implementation of the law. It serves to emphasize that law cannot play a central role in addressing women's discrimination issues and that other interventions through policy, programmes and public education at the family, community, and institutional levels are equally important, as is the participation of all these sectors in such initiatives.

A Systems thinking approach of seeing the connections, links, or relationships between all related elements will help in providing a comprehensive solution to the menace of sexual harassment. Instead of seeing parts and pieces of the problem, it allows the interdependent whole to be appreciated. An understanding the interrelationships among key components of a system will assist us in providing inclusive, long term solutions. 
Systems' thinking is a powerful approach for understanding the nature of why situations are the way they are, and how to go about improving results. Systems' thinking is not an easy approach for it requires a substantial investment of effort, and thought, though the results can be more than worth the investment.

\section{References}

[1]. Avani Mehta Sood, G (2008).ender Justice through Public Interest Litigation: Case Studies from India, Vand. J. Transnat'1 . 833, 866-875

[2]. Apparel Export Promotion Council v. A.K. Chopra, A.I.R. 1999 S.C. 625 (India).

[3]. Bina Srinivasan, (1999), Dealing with sexual harassment at the workplace: Impasse Continues, 34(37) Econ. \& Pol. Wkly.

[4]. CEDAW (1992) Committee. General Recommendation No. 19. para. 17. Further Actions and Initiatives to Implement the Beijing Declaration and Platform for Action. (2000).A/RES/S-23/3. para. 59.

[5]. Fitzgerald, L. F., \& Shullman, S. L. (1993). Sexual harassment: A research analysis and agenda for the 1990s. Journal of Vocational Behavior, 42, 5-27.

[6]. Fitzgerald, L. F., Shullman, S. L., Bailey, N., Richards, M., Swecker, J., Gold, Y., et al. (1988). The incidence and dimensions of sexual harassment in academia and the workplace. Journal of Vocational Behavior, 32, 152-175.

[7]. Fitzgerald, L. F., Swan, S., \& Fischer, K. (1995). Why didn't she just report him? The psychological and legal implications of women's responses to sexual harassment. Journal of Social Issues, 51, 117-138.Folkman, S., \& Lazarus, A. (1989). Manual for the Ways

[8]. Gaule, Hemant, Jinmay Joshi, Robin Antony, Shankar N, and Varma Deepkumar. (2009) "Violence Against Women, The Nari Adalat, Gujarat." (1996) Scribd. N.p., 17 Mar. General Surveys on Equality in Employment and Occupation Convention. International Labour Organisation.. para. 40.

[9]. Gruber, J. E. (1989). How women handle sexual harassment: A literature review. Sociology and Social Research, 74, 3-9.

[10]. Gruber, J. E., \& Bjorn, L. (1986). Women's responses to sexual harassment: An analysis of sociocultural, organizational and personal resource models. Social Science Quarterly, 67, 814-826.

[11]. Gruber, J. E., \& Smith, M. D. (1995). Women's responses to sexual harassment: A multivariate analysis. Basic and Applied Social Psychology, 17, 543-562.

[12]. India. National Crime Records Bureau. Ministry of Home Affairs. (2011) Crime in India Statistics. New Delhi

[13]. International Labour Organisation. Technical report for discussion. (2001) ILO-Japan Regional Tripartite Seminar on Action against Sexual Harassment at Work in Asia and the Pacific.. (From here on referred to as the ILO Technical Report)

[14]. Khazan, Olga, and Rama Lakshmi. (2012.) "10 Reasons Why India Has a Sexual Violence Problem." Weblog post. WorldViews. Washington Post.

[15]. Krishnan, Suneeta. (2013) "India Gang Rape: How to Reduce Violence against Women." The Christian Science Monitor. The Christian Science Monitor

[16]. Medha Kotwal Lele \& Ors. vs. UOI \& Ors., Order dated 26.04.2004. Writ Petition (Crl.) Nos. 173-177/1999,

[17]. Michael Rubenstein, (August 2000) cited in Business Age, .Not a Normal Behavior, . Vol. 2 No 9

[18]. Nelien Haspels, Zaitun Mohamed Kasim,(2003) Constance Thomas and Deirdre McCann, Action against Sexual Harassment at Work in Asia and the Pacific. ILO, Bangkok Area Office and East Asia Multidisciplinary Advisory Team.

[19]. Nivedita Menon, ((2004), Recovering Subversion: Feminist politics beyond the law 145

[20]. Paramita Chaudhuri, (2006) Sexual Harassment in the Workplace: Experiences of Women in the Health Sector, 28-29 (Health \& Population Innovation Fellowship Programme, Working Paper No. 1.

[21]. Pratiksha Baxi, (2001) Sexual Harassment, 505 Seminar 54, 54-59, available at http://www.india-seminar.com/2001/505/505

[22]. Rema Nagarajan, (2012). "Seven out of ten women sexually harassed", TNN .

[23]. Nari (2003), Role of NGO in Effective Implementation of PFA and CEDAW in Bangladesh,

[24]. Rupan Deol Bajaj v. K.P.S. Gill, A.I.R. 1995 S.C. 309 (India).

[25]. ILO/FWLD Report. 2004, Sexual Harassment at the Workplace in Nepal

[26]. HC, TIMES OF INDIA, Oct. 6, 2009 Sexual Harassment at Work Can't Be Taken Lightly:

[27]. Williams Petrocelli and Barbara Kate Repa, ( 1992.)Sexual Harassment on the Job. By Attorneys,

[28]. Sheba Tejani, (2004),Sexual Harassment at the Workplace: Emerging Problems and Debates, 39(41) ECON. \& POL. WKLY., Oct. 9 , , at 4491 .

[29]. Vishaka v. State of Rajasthan, (1997) 6 S.C.C. 241 (India) 